\title{
Turizm İşletmelerinde Bilgi ve İletişim Teknolojilerinden Blokzincir Teknolojisine Geçiş Süreci ve Uygulama Örnekleri
}

\author{
Senem Yazıc1 ${ }^{*}$ \\ *Muğla Sttk1 Koçman Üniversitesi, Turizm Fakültesi, Turizm İşletmeciliği Bölümü, Muğla, Türkiye, (ORCID: 0000-0002-1318-3462), senemyazici@mu.edu.tr
}

(İlk Geliş Tarihi 8 Ekim 2020 ve Kabul Tarihi 24 Aralık 2020)

(DOI: $10.31590 /$ ejosat.807716)

ATIF/REFERENCE: Yazıc1, S. (2021). Turizm İşletmelerinde Bilgi ve İletişim Teknolojilerinden Blokzincir Teknolojisine Geçiş Süreci ve Uygulama Örnekleri. Avrupa Bilim ve Teknoloji Dergisi, (21), 136-146.

$\ddot{O} \mathbf{z}$

Turizmde bilgi ve iletişim teknolojileri kullanımı çok eski ve gelişmiştir. Bilgi ve iletişim teknolojisi turizm ürünlerinin aracı turizm işletmelerine ulaşabilmesini sağlayan dağıtım ağlarının kurulmasını sağlamıştır. Bu dağıtım ağları dünya genelinde dört büyük firmanın merkezi sistemde kontrolü altındadır. Blokzincir, turizm işletmelerinde dağıtım ağını ve iş modelini tamamen değiştirecek yıkıcı bir teknolojidir. Turistin merkezsiz, güvenlikli, şeffaf ve aracısız işlem talebi turizm altyapısının değişmesinin gerekliliğini ortaya koymaktadır. Ancak, turizm işletmelerinde blokzincir teknolojisinin benimsenmesi ve uygulama alanı bulması oldukça yavaş olmuştur. Bu makalenin amacı turizm işletmeciliğinde bilgi ve iletişim teknolojisinden blokzincir teknolojisine geçiş sürecini ve turizmde blokzincir uygulama örneklerini incelemektir. Ayrıca, blokzincir teknolojisinin turizm işletmelerinde çok çeşitli uygulama firsatları sunduğunu ortaya koymaktır. Araştırmada nitel araştırma yöntemlerinden alanyazın taraması yapılarak turizmde blokzincir kavramının detaylı ve derinlemesine araştırılmıştır. Kavramsal çerçevenin oluşturulabilmesi için, araştırmada "blokzincir" ve "turizm" anahtar kelimeleri geçen yazılı belgeler ayrıntılı olarak taranarak doküman analizi gerçekleştirilmiştir. Turizm işletmeciliğinde bilgi ve iletişim teknolojisinden blokzincir teknolojisine geçiş süreci kronolojik ve tarihsel olarak değerlendirilmiştir. Turizmde uygulanan blokzincir teknoloji uygulamaları ve örnekleri incelenmiştir. Elde edilen alanyazın bulguları 1şı̆̆ında, blokzincir teknolojisinin turizmin karmaşık ve çok aracılı ürün dağıtım ağında oluşan güvensizlik, şeffaflık ve merkezi sistemden kaynaklanan sorunları çözmede önemli bir yere sahip olacağı anlaşılmaktadır. Turizm işlemleri, blokzincir teknolojisi kullanılarak daha şeffaf, açık, güvenli ve merkezi olmayan bir sisteme geçebilecektir. Diğer taraftan, alanyazın bulguları blokzincir uygulamalarının teknoloji firmaları tarafından geliştirilmekte olduğunu; turizm işletmelerinin altyapılarının bu tür yıkıcı teknolojileri kurgulama ve uygulamada yetersiz kaldığını göstermektedir. Bu sorunun giderilmesinde, üniversitelere önemli rol düşmektedir. Teknoloji Transfer Ofisleri, Blokzincir Araştırma Merkezleri, Turizm Araştırma Merkezleri ve Turizm İşletmeleri blokzincir uygulamalarının geliştirilmesinde birlikte çalışarak turizm işletmelerine büyük katkı sağlayabilirler. Sonuç olarak, blokzincir teknolojisi ile yeniden yapılandırılacak iş modelleri turistler, turizmde çalışanlar ve turizm işletmecileri için turizm işleyişini ve ekosistemi kökten değişecektir.

Anahtar Kelimeler: Blokzincir Teknoloji, Turizm İşletmeleri, Bilgi ve Iletişim Teknolojileri, Merkezsiz, Şeffaf.

\section{The Process of Transition from Information and Communication Technologies to Blockchain Technology in Tourism Management and Application Examples}

\begin{abstract}
The use of information and communication technologies in tourism is very old and well developed. Information and communication technology has enabled the establishment of distribution networks that enable tourism products to reach intermediary tourism enterprises. These distribution networks are under the central control of four major companies worldwide. Blockchain is a disruptive
\end{abstract}

*Sorumlu Yazar: senemyazici@mu.edu.tr 
technology that will completely change the distribution network and business model in tourism businesses. The demand of the tourist for decentralized, secure, transparent and unmediated transactions reveals the necessity of changing the tourism infrastructure. However, the adoption and application of blockchain technology in tourism businesses have been rather slow. This article aims to examine the transition process from information and communication technology to blockchain technology in tourism management and blockchain applications in tourism. It is also to reveal that blockchain technology offers a wide variety of application opportunities in tourism businesses. In the research, the concept of blockchain in tourism was investigated in detail and in-depth by scanning the literature, one of the qualitative research methods. Document analysis was performed by scanning written documents containing the keywords "blockchain" and "tourism". The process of transition from information and communication technology to blockchain technology in tourism management has been evaluated chronologically. Blockchain technology applications and examples applied in tourism were examined. In the light of the findings of the literature, it is understood that blockchain technology will have an important place in solving the problems arising from insecurity, transparency and central system in tourism's complex and multimediated product distribution network. Tourism transactions will be able to move to a more transparent, open, secure and decentralized system using blockchain technology. On the other hand, the findings of the literature show that blockchain applications are being developed by technology firms; It shows that the infrastructures of tourism enterprises are insufficient to construct and implement such disruptive technologies. Universities play an important role in overcoming this problem. Technology transfer offices, blockchain research centres, tourism research centres and tourism enterprises can make a great contribution to tourism businesses by working together in the development of blockchain applications. As a result, business models to be restructured with blockchain technology will radically change the functioning and ecosystem of tourism for tourists, tourism workers and tourism operators.

Keywords: Blockchain Technology, Tourism Management, Information and Communication Technology, Decentralized, Transparent.

\section{Giriş}

Blokzinciri son yüzyılın en önemli buluşlarından birisi olarak kabul edilmektedir (Durbilmez ve Türkmen, 2017). 2008 yılında Blokzincir teknoloji ile çalışan 'bitcoin' kripto para Satoshi Nakamoto tarafından Dünya'ya hibe edilerek ekonomiyi, teknolojiyi ve para kullanımını tamamen değiştirmiştir (Tanrıverdi, Uysal ve Üstündağ, 2019). Satoshi Nakamoto'nun kim ya da kimler olduğu belirlenememiştir (Valeri, 2020). Blokzinciri şifreleme, oyun teorisi ve bilgisayar mühendisliğinin birleşmesi sonucunda ortaya çıkmış bir teknolojidir (Brandenburger vd., 2018). Nakamoto'nun (2008) elektronik para üzerine çalışmalarını sürdürürken (Bitcoin geliştirilme aşaması) yaşanan bir problem, blokzincirinin kullanılmasına neden olmuştur. Nakamoto (2008) eşten eşe elektronik para sistemininde yaşanan problemi "dijital para sisteminde para mükerrer olarak kullanılmadığının doğrulanmasının merkezi sistem olmadan nasıl yapılacağının bilinmemesi” olarak belirtmiştir. Çifte harcama problemi (double-spend problem) olarak bilinen bu problemi çözmek için 'açık anahtar şifreleme', 'dijital imza', 'hash' (bilgisayar terminolojisinde karma ya da özet anlamında kullanılır) ve 'iş kanıtı' olarak bilinen 'uzlaşma algoritması' kullanılarak blokzincir teknolojisi kullanılmıştır (Pilkington, 2017; Karaarslan and Akbaş, 2017).

Blokzincirinin elektronik para Bitcoin ile anılmasının iki nedeni vardır. Bunlardan ilki, merkezi sistemden merkezsiz sisteme geçilmesi ve ikincisi ise güvenilir para transferlerinin aracı olmadan yapılabilmesinin ispatlanmış olmasıdır (Varelas, Georgitseas, Nechita ve Sahinidis, 2019). Bu ispatın üzerinden geçen on yıllık sürede, blokzinciri teknolojisine karşı önyargılar olmasına karşın ekonomik çevrede güven kazanmıştır (Özpınar, 2020). Bu güvenin oluşmasında temel nedenlerin başında blokzinciri hiçbir zaman kapatılamaz, silinemez ve yok edilemez bir yapıya sahip olması gelir (Avunduk ve Aşan, 2018). Teorik olarak blokzinciri tek bir düğümde çalışabilmeye ayarlanmış olsa; elektrik kesintisi, bilgisayar korsanları veya sistemik çökmeler gibi tehditlere karşı son derece savunmasız kalabilir (Brandenburger, Cachin, Kapitza ve Sorniotti, 2018). Bir blokzinciri ne kadar çok sayıda düğüm kullanıyorsa, bu tür felaketlere karşı dayanıklılığ o kadar iyi anlamına gelmektedir
(Lin ve Liao, 2017). Bir bilgisayarın bir kısmına ulaşılamadığ durumlarda blokzincir geçmişi bulunan bir düğümün dağıtık ağ ile bağlanarak birçok cihaza yayılması ile sistem aktif hale gelebilmektedir (Rejeb ve Karim, 2019). Bundan dolay1 blokzincir eşsiz ve güvenli bir teknolojik altyapı sunmaktadır.

Blokzincir ilk çıktığı 2008 yılından itibaren; 'Blokzincir 1.0', 'Blokzincir 2.0' ve 'Blokzincir 3.0' olmak üzere üç farklı evrede gelişmiştir (Lu, 2018). Blokzincir 1.0 'Para Birimi bitcoin' dönemi olup kripto para, para transferleri, havale ve ödemeler için dijital sistemlerin oluşumunu ifade eder (Özpınar, 2020). Bir diğer ifade ile bankaların, finansal aracı ve yatırımcı kurumların dijital para transferlerini gerçekleştirmesidir (Tanriverdi vd., 2019). Blokzincir 2.0 ile 'Akıllı Sözleşmeler' devri olarak bilinen ve ekonomik olarak hisse senetleri, tahviller, vadeli işlemler, krediler, ipotek, unvanlar, akıllı mülkler ve akıllı sözleşmelerden oluşan her tür işlemin dijitalleşmesi olarak kabul edilmektedir (Taş ve Kiani, 2018; Karaarslan ve Konacakli, 2020). Blokzincir 3.0 ise 'Yeni Kullanım' alanlarında yaygınlaşmasıdır. $\mathrm{Bu}$ çerçevede hükümet, sağlık, bilim, okuryazarlık, sanat, kültür, askeri ve tedarik zinciri sistemleri ve benzeri alanlar ile ekonominin haricinde kalan diğer alanlarda kullanımı arttı (Tanrıverdi vd., 2019; Aydar ve Çetin, 2020; Angın, 2020). Blokzinciri ekonomi (Jantoń-Drozdowska ve Mikołajewicz-Woźniak, 2017); sigorta (Gatteschi, Lamberti, Demartini, Pranteda ve Santamaría, 2018); açık artırma (Brandenburger vd., 2018) ve nesnelerin interneti (Kösesoy, 2019) gibi birçok alanda başarılı bir şekilde kullandığını gösteren uygulamalar ve çalışmalar yapılmıştır. Blokzincirinin ürettiği çözümler arasında envanter yönetimi, sadakat yönetimi, rezervasyon, biletleme, dijital ödemeler, yüz ve kimlik tespit yönetimi yer almaktadır (Erceg, Damoska Sekuloska ve Kelić, 2020).

Blokzinciri teknolojisini benzersiz yapan özellikler arasında merkezsizlik (merkezi olmayan kontrol), zaman (işlem süresi), değişmez veri, güvenlik ve dijitalleşme gelmektedir (Kösesoy, 2019). Karaarslan ve Akbaş (2017) blokzincir teknolojisinin kullanımında en önemli faktörün "veri" olduğunu vurgulamaktadırlar. İşletme sahipleri ya da yöneticileri verinin kullanımına göre blokzincir kullanımına karar vermeye çalışırken; kullanıcıların korunması gereken haklarını, güvenliklerini ve işlemlerin şeffaflığını garanti altına alınmasını 
da göz ardı edilmemelidir (Guo ve Liang, 2016). Kullanıcı boyutundan bakıldığında, blokzinciri insanlar arasında oluşan güvensizliğin ortadan kalkmasını sağlayacak bir alt yap1 sağlamaktadır. Güvenliği sağlamanın yanında kişilerin kişisel haklarını ve mahremiyetlerini de korumaktadır (Karaarslan ve Akbaş, 2017). Aracı ve merkezi sistemleri kaldırarak, kendi kendini yöneten bir sistem oluşturmaktadır. Tanrıverdi vd. (2019: 210) blokzinciri kullanmanın avantajlarını "veri kaybı ve tahribatının önlenmesi, paydaşların birbirine olan güvenini artırması, şeffaflık, değiştirilememesi, silinememesi, kontrol edilemez işlemleri otomatikleştirilmesi (akıllı sözleşmeler), iptal edilemez ve kapatılamaz" olarak belirtmektedirler. Diğer tarafta ise fazla enerji tüketimi, çok pahalı bilgisayar sistemleri ve performans yetersizliği dezavantajları arasında sıralanabilir (Taş ve Kiani, 2018; Sirka, Erdelyi, Cicak and Jelemenska, 2019; Tanrıverdi vd., 2019; Karaarslan ve Konacakli, 2020).

Günümüzde, ulusal ve uluslararası işletmeler sabit bir yerde yaşayan merkezi bir veri tabanı kullanmaktadırlar (JantońDrozdowska ve Mikołajewicz-Woźniak, 2017). Facebook, Wikipedia, Ebay, Twitter, AirBnB gibi platformlar merkezi sistemler kullanmaktadırlar. Accenture (sigorta) ve Ripple (kripto para ödeme merkezi çözümleri) dağıtık ağ kullanmaktadırlar (Pilkington, 2017). Bankalar, zincir oteller gibi işletmeler merkezi ağ ile merkeze bağlıdırlar (Önder ve Treiblmaier, 2018). Durbilmez ve Türkmen (2017) merkezi ağlarda kullanılan veri tabanlarının ya da sunucuların çok kolay kötü niyetli kişilerin eline geçebileceğini ve güvenli olmadığ konusuna dikkat edilmesini gerektiğini belirtmişlerdir. 2019 yılında, Türkiye Kişisel Verileri Koruma Kurumu "Kişisel Verileri Koruma Kanunu" çerçevesinde merkezi ağlar ile çalışan British Airways, Cathay Pasifik Airway ve Marriott otel zincirine veri güvenliğini sağlayamadıkları ve ihlal ettikleri için 550,000 TL ile 1,450,000TL arasında cezalar vermiştir (KVK, 2019). Kişisel veriler turizm işletmeleri için toplanan ve güvenli olarak saklanamayan büyük bir sorun haline gelmiştir. Turistin kişisel verilerini koruyabilmek ve yüksek cezalar ödememek için 2010 yılından itibaren blokzincirinin bu sorunların çözümünde kullanılıp kullanılamayacağı tartışılmaya başlanılmıştır (Guo ve Liang, 2016; Antoniadis, Spinthiropoulos ve Kontsas, 2020). 2017 yılından itibaren blokzincir teknolojisi kişisel verilerde yaşanan güvenlik açıkları ve problemlerin ortadan kaldırılmasında çözüm örnekleri oluşturmaya başladı (Lin ve Liao, 2017; Angin, 2020).

Turizm işletmelerinde ilk kullanıcıdan son kullanıcıya kadar çok karmaşık bilgi ve iletişim sistemleri kullanılır (Keskinkılıç, Ağca ve Karaman, 2016; Buhalis vd., 2019). Bilgi ve iletişim teknolojilerini dağıtım ağında çok iyi kullanan turizm işletmeleri, blokzincir gibi çok ileri teknolojilerde henüz istenen seviyeye ulaşmamıştır. Yerli alanyazınında blokzinciri ve turizm alanında çalışmalar (Gültekin, 2017; Ulusoy ve Dönmezi, 2018; Yıldız ve İbiş, 2019) henüz başlangıç aşamasında olmasına rağmen; yabancı alanyazınında blokzincir teknolojisinin kullanımı turizm de dâhil birçok alanda hızla artmaktadır (Önder ve Treiblmaier, 2018; Rejeb ve Karim, 2019; Buhalis, Harwood, Bogicevic, Viglia, Beldona ve Hofacker, 2019). Turizm gibi geniş yelpazede hizmet veren işletmelerde hangi alanlarda blokzincir uygulamalarının başarılı olacağı araştırılmaktadır (Gültekin, 2017; Önder ve Treiblmaier, 2018). Blokzinciri teknolojisinin turizmde var olan birden fazla aracı, merkezi sistem, güvensizlik gibi ana temel sorunlara çözüm olabilir (Varelas vd., 2019). Bu çerçevede, bu derleme araştırmasında turizm ve blokzincir alanyazınlarını harmanlayarak turizmde blokzincir teknolojisi kavramının geliștirilmesinde farklı bir bakış açısı getirerek alana katkı yapılması planlanmaktadır.

\section{Materyal ve Metot}

Araştırmanın amacı turizm işletmelerinde bilgi ve iletişim teknolojisinden blokzincir teknolojisine geçiş sürecini ve uygulama örneklerini alanyazın incelemesi ile kavramsal bir çerçeve oluşturmaktır. Bu araştırmada "blokzincir teknolojisi turizm işletmeciliğinde yaşanan sorunlara nasıl çözüm üretebilir?" sorusuna yanıt aranacaktır. Araştırmanın derinlemesine ve detaylı bilgiler verebilmesi amacı ile nitel araştırma yöntemi kullanılmıştır. Nitel araştırmalarda sıklıkla kullanılan alanyazın taraması yöntemi iki farklı disipline ait alanlarda gerçekleştirilmiştir. Bu çerçevede, blokzincir araştırma ve uygulamalarının en yoğun olduğu 2010-2020 yılları arasını kapsayan alanyazın incelemesi yapılmıştır. Araştırmada "Blokzincir", "Bilgi ve İletişim Teknolojileri" ve "Turizm" anahtar kelimeler (İngilizce ve Türkçe) dokümanların başlığında ya da metin içinde geçmesi halinde incelemeden geçirilmiştir. Önce turizm işletmeciliğinde bilgi ve iletişim teknolojisi sonra blokzincir teknolojisi kronolojik olarak değerlendirilmiştir. Dünya genelinde turizm işletmelerinde blokzincir uygulama örnekleri Amadeus (2017), Anushya (2019) ve Tham ve Sigala (2020) çalışmalarından yararlanılarak tespit edilmiştir. Elde edilen nitel verilere içerik analizi yapılmıştır.

\section{Araştırma Sonuçları ve Tartışma}

\subsection{Blokzincir Teknolojisi Alanyazın İncelemesi}

Blokzincirin ilk tanımı Satoshi tarafindan 2008 yılında yayınladığı raporda yapılmıştı (Satoshi, 2008). Fakat, Buterin (2015) kullanılan bitcoin tanımında 'kayıt, para, işlem, dağıtık, defter' kelimelerinin kullanılmadığını ve bundan dolayı anlaşılmayacağını belirterek yeni bir tanım ortaya atmıştır. Buterin (2015: 1) blokzinciri “...herkesin programları yükleyebileceği ve programları her programın mevcut ve önceki tüm durumlarının her zaman herkes tarafindan görülebildiği ve zincir üzerinde çalışan programların çok güçlü kripto ekonomik olarak güvence altına alındığı yerlerde kendi kendini yürütmeye bırakabileceği sihirli bir bilgisayar" olarak tanımlamıştır. Iansiti ve Lakhani (2017: 1) ise blokzinciri tanımını "bitcoin'in ve diğer sanal paraların kalbindeki teknoloji olan blockzinciri; iki taraf arasındaki işlemleri verimli ve doğrulanabilir ve kalıcı bir şekilde kaydedebilen açık, dağıtılmış bir defterdir. Defter kendisi de işlemleri otomatik olarak tetikleyecek şekilde programlanabilir" şeklinde yaparak daha açıklık ve netlik kazandırmıştır. Ayrıca bu tanımdan yola çıkarak blokzincirinin beş temelinin dağıtılmış defter, açık ve paylaşılan (herkese açık), doğrulanabilir, işlemler ve merkezsizlik olduğu netleşmiştir (Karaarslan ve Konacakli, 2020). Şekil 1'de görüldüğü gibi, blokzinciri üç ana temel olan 'özerklik, doğrulanmışlık ve değişmezlik’ üzerine kurulmuştur (Hackius ve Petersen, 2017). 
Sekil 1: Blokzincir'in 3 temel özelliği

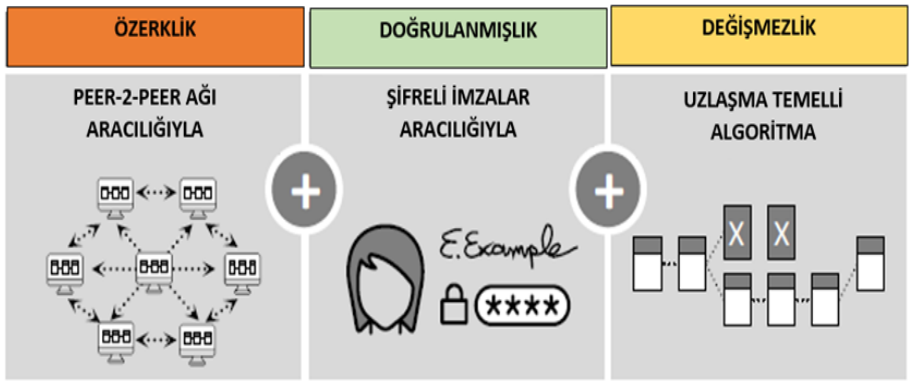

Kaynak: Hackius ve Petersen (2017); Türkçe'ye Çeviren Bakan ve Şekkeli (2016).

Şekil 1'de belirtildiği gibi blokzincirinin üç temeli vardır ama arkasında komplike çalışma prensipleri de bulunmaktadır. Blokzincir teknolojisinin altında eşten eşe ağ, açık-kapalı anahtar şifreleme ve uzlaşma algoritmasının mükemmel bir şekilde bir araya gelmesi yatmaktadır (Buterin, 2015; Hackius ve Petersen, 2017; Filippi and Wright, 2018; Wang vd., 2019; Karaarslan ve Konacakli, 2020). Blokzincir teknolojisinin çalışmasında internet ağ sisteminin tamamen değişmesi çok önemli bir rol oynar (Şekil 2). Blockzincir teknolojisinin diğer kullanılan sistemlerden en önemli farkları ise açık, şeffaf ve değiştirilemez olmasının yanında aracı kurum ya da kişilerin olmamasıdır (doğrulayıc1) (Dogantekin, 2016; Gainsbury ve Blaszczynski, 2017).

Şekil 2: Blokzincir çalışma prensibi Merkezi Olmayan Doğrulama-

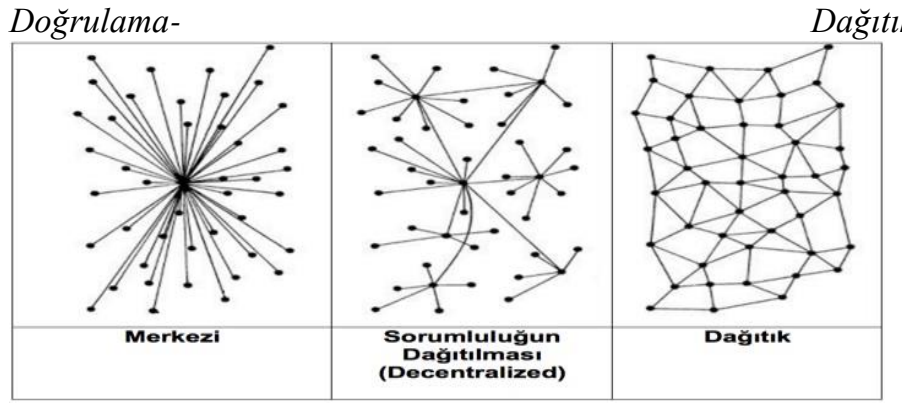

Kaynak: TUBITAK BİLGEM (2019)
Şekil 2' de görülen noktalar ağı oluşturan eşe ait düğümleri (node) yani bir bilgisayarı, laptopu, küçük ya da büyük hizmet sağlayıcı bilgisayarı temsil etmektedir (Durbilmez ve Türkmen, 2017). Bir bilgisayar eğer "tüm düğüm" olarak adlandırılıyor ise bu blokzincirindeki bütün işlemlerin geçmiş kayıtlarına sahip demektir (Casey ve Vigna, 2018). Merkezi (centralized), merkezi olmayan (decentralized) ve dağıtık (Distributed) ağ sistemleri olarak üç türü vardır (Alam, 2019). Kösesoy (2019) blokzincir teknolojisinde verinin "birbirine P2P ağı ile bağlı birden fazla bilgisayar üzerinde" tutulduğunu ve bundan dolayı dağıtık ağ olduğunu belirtmektedir.

Blokzincirinde her işlemin güvenli, şeffaf ve kayıt altına alınabilmesinin arkasında hesap defterleri teknolojisinin dağıtık olarak bulunması yatmaktadır (Eljazzar, Amr, Kassem ve Ezzat, 2018). Belin (2019) blokzincir teknolojisi ile hesap defterleri teknolojisinin karıştırıldığını savunmaktadır. Aslında, hesap defterleri (ledgers), para ile işlem yapan ve yaptıranın herkesin bildiği çok eski bir yazılı kayıt sistemidir (Ebel ve Özel, 2005). Gökgöz (2011) hesap defterlerinin tutulması insan hafizasına güvenilmemesinden ve işlemlerin kayıt altına alınması gerekliliğinden başladığını belirtmektedir. Dahan ve Casey (2016) hesap defterlerinin çok eski olduğunu ve zaman içerisinde değişime uğradığını bundan dolayı kayıt tutulduğunu belirtmektedir.

Tablo 1'de dağıtık defter teknolojisinin y1llar itibari ile gelişimi detaylı verilmektedir. Dağıtılmış defter teknolojisi çeşitli yerlerde veya birden fazla katılımcı arasında bulunan bir veritabanı olup muhasebede kullanılan kayıt defteleri gibi işlenmektedir (Collomb ve Sok, 2016; Dahan ve Casey, 2016; Casey ve Vigna, 2018). Eljazzar, Amr, Kassem ve Ezzat (2018) hesap defterlerini "merkezi bir yöneticisi ya da veri deposu olmayan; coğrafi olarak birden fazla alana, ülkeye veya kuruma yayılan; çoğaltılarak, paylaşılan ve senkronize edilebilen verilerin fikir birliği tutulan dijital kayıtlardır" olarak tanımlamaktadır. Dahan ve Casey (2016) blockzincirinin dağıtık hesap defteri (DHD) olmadığını ve sadece bir türü olduğunu belirtmektedir. Casey ve Vigna (2018) blokzincirinin ve dağıtık hesap defterinin birlikte çalışmalarına rağmen farklı teknolojiler olduğunu savunmaktadırlar. $\mathrm{Bu}$ durum diğer dağıtık hesap defteri türlerinin gelişmesine de öncülük etmiş olmaktadır.

Tablo 1: Dă̆ıtık Defter Teknolojisi

\begin{tabular}{|c|c|c|c|c|c|}
\hline $\begin{array}{l}\text { Tahmini } \\
\text { Zaman }\end{array}$ & $\begin{array}{c}\text { Tariben } 500 \\
\text { MS } \\
\end{array}$ & $\begin{array}{c}\text { Tariben } 700 \\
\text { MS }\end{array}$ & 11. Yüzyıl & 21. Yüzyıl & Gelecek \\
\hline $\begin{array}{c}\text { Güvence } \\
\text { veren (Kefil, } \\
\text { Garantör) } \\
\end{array}$ & $\begin{array}{c}\text { Kabile } \\
\text { Şefi/Krallığın } \\
\text { Başadamı } \\
\end{array}$ & $\begin{array}{c}\text { Merkezi } \\
\text { Otorite }\end{array}$ & $\begin{array}{l}\text { Devlet ya da } \\
\text { Banka }\end{array}$ & $\begin{array}{c}\text { Merkez Bankası ve Ticari } \\
\text { Bankalar }\end{array}$ & $\begin{array}{c}\text { Merkezsiz Bilgisayar } \\
\text { Ağları }\end{array}$ \\
\hline Hesabi Tutan & $\begin{array}{l}\text { Kabile } \\
\text { Şefinin } \\
\text { Hafizası }\end{array}$ & Çetele & $\begin{array}{c}\text { Bilanço/ } \\
\text { Kağıtla Kayıt }\end{array}$ & $\begin{array}{c}\text { Bağımsız elektronik hesap } \\
\text { defterleri }\end{array}$ & $\begin{array}{l}\text { Dağıtık, paylaşımlı } \\
\text { herkese açık hesap } \\
\text { defterleri }\end{array}$ \\
\hline Yayımlayan & Kabile Şefi & $\begin{array}{c}\text { Merkezi } \\
\text { Otorite }\end{array}$ & Banka & Merkez Bankası & $\begin{array}{l}\text { Dijital Para } \\
\text { Algoritmas1 }\end{array}$ \\
\hline $\begin{array}{c}\text { Paranın } \\
\text { göstergesi }\end{array}$ & $\begin{array}{c}\text { Rai (Fei) taş } \\
\text { para }\end{array}$ & $\begin{array}{l}\text { Pirlanta ve } \\
\text { Değerli } \\
\text { metaller }\end{array}$ & $\begin{array}{c}\text { Hükümet } \\
\text { kararına dayanan } \\
\text { kâğıt para (Yasal } \\
\text { Para) }\end{array}$ & $\begin{array}{c}\text { Hükümet kararına dayanan } \\
\text { kâğıt para + Dijital Para olarak } \\
\text { Banka/Kredi Kartları }\end{array}$ & $\begin{array}{l}\text { Dijital Para } \\
\text { /Kriptopara } \\
\text { (Bitcoin) }\end{array}$ \\
\hline
\end{tabular}

Kaynak: Yazar tarafından Dahan ve Casey (2016) ve Casey ve Vigna (2018) çalışmalarından adapte edilmiştir. 
Blokzinciri teknolojisinin hangi sorunların çözümünde kullanılabileceği üzerine tartışmalar devam etmektedir (Karaarslan ve Konacakli, 2020). Yöneticilerin ya da işletme sahiplerinin iş alanlarına ve farklı sorunlara göre farklı çözümler üretmeleri gerekebilir. Yapılan araştırmalar çok net bir şekilde blokzinciri teknolojisinin her tür sorunu çözemeyeceğini, hatta uygun olmayacağını belirtir (Wüst ve Gervais; 2017; Pannier,
2018; Unsal ve Kocaoglu, 2018). Blokzincir dört farklı şekilde oluşturulur (Usta ve Doğantekin, 2017). Swarn (2015) tarafindan oluşturulan ve TUBITAK BİLGEM (2019) tarafından Türkçe çeviri yapılan blokzincir kullanıp kullanmama diyagramında; üç blokzincir türü ve duruma göre hangi tür blokzincirin tercih edilmesi gerektiği şekil 3 'te belirtilmektedir.

Şekil 3: Blokzincir kullanmalı mısınız?

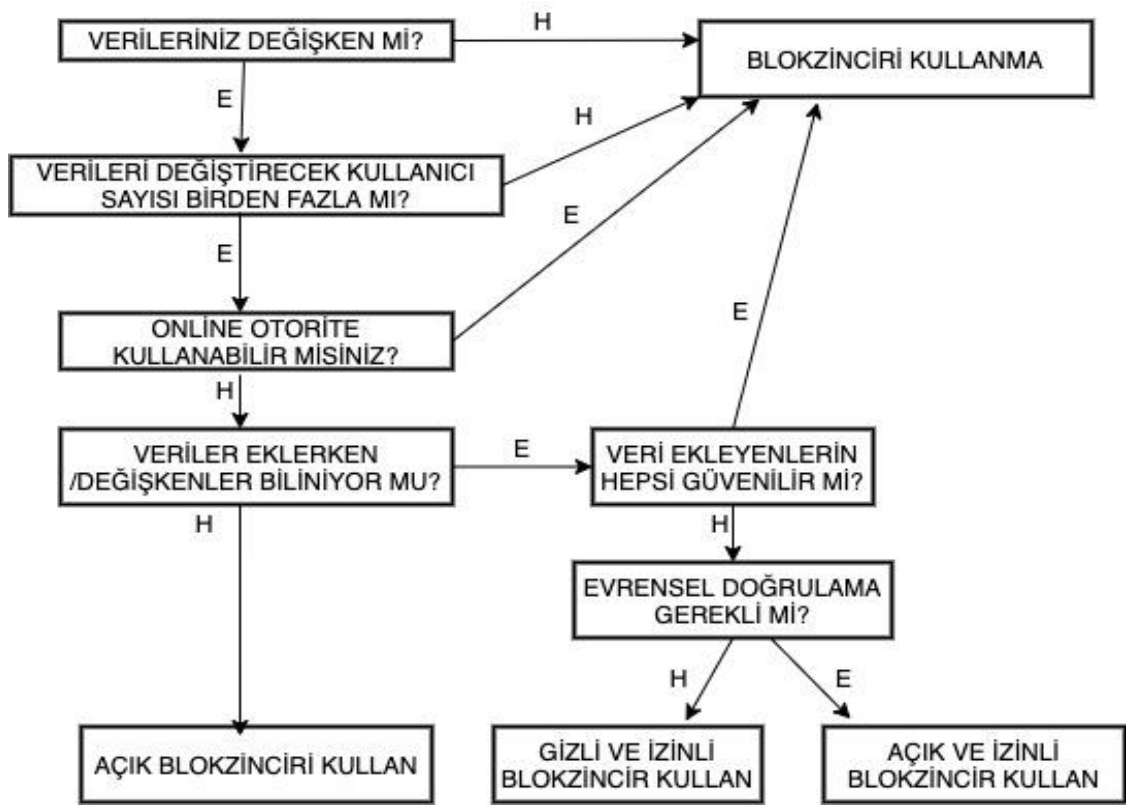

Kaynak: Wist ve Gervais (2017); Türkçe çevirisi TÜBİTAK BİGEM (2019) (E-Evet/H-Hayır)

Açık ve özel blokzincir türlerinin bazı örnekleri platform üzerinden bazıları yazılımlar ile yürütülmektedir. Blokzincir türlerinin arasında en iyi bilineni açık blokzincir ağ "Bitcoin" elektronik para sistemidir (Nofer, Gomber, Hinz ve Schiereck, 2017). Hileman'nın (2016) belirttiği gibi "Ethereum ve Bitcoin" hem açık blokzinciri hem de platform; "Ripple ve Blockstream" özel blokzinciri ve platform; "Hyperledger Project" açık blokzincir ve yazılım; son olarak "DGigital Asset ve Eris" ise özel ve yazılımdır. Wüst ve Gervais (2017) her iş modeline Blokzincirin çözüm olmayacağını vurgulamaktadır.

Karaarslan ve Akbaş (2017) blokzincir teknolojisinin kullanımında en önemli faktörün "veri” olduğunu vurgulamaktadırlar. İşletme sahipleri ya da yöneticileri veri ile ilgili sorulara göre blokzincir kullanımına karar vermeye çalışırken; kullanıcıların korunması gereken haklarını, güvenliklerini ve işlemlerin şeffaflığını garanti altına alınmasını da göz ardı etmemelidirler (Guo ve Liang, 2016). Kullanıcı boyutundan bakıldığında, blokzinciri insanlar arasında oluşan güvensizliğin ortadan kalkmasını sağlayacak bir alt yapı sağlamaktadır. Güvenliği sağlamanın yanında kişilerin kişisel haklarını ve mahremiyetlerini de korumaktadır (Mustaçoğlu, 2018). Blokzinciri teknolojisini benzersiz yapan özellikler arasında merkezsizlik (merkezi olmayan kontrol), zaman (işlem süresi), değişmez veri, güvenlik ve dijitalleşme gelmektedir (Kosesoy, 2019). Aracı ve merkezi sistemleri kaldırarak, kendi kendini yöneten bir sistem oluşturur. Böylece, kripto para ve bankacılık haricinde blokzinciri teknolojisini farklı alanlarda kullanılma imkânı oluşur (Belin, 2019; Özpınar, 2020).

\subsection{Turizm İşletmelerinde Bilgi ve İletişim Teknolojileri Alanyazın İncelemesi}

İnternet turizmi yapısal, köklü ve geri dönüşü olmayan şekilde tamamen değiştirmiştir (Buhalis vd., 2019). Turizm işletmeleri bilgi ve iletişim teknolojilerini uzun yıllardır kullanmalarından dolayı; internet ile oluşan yeni 'Dijital Dünya' ile rahatlıkla uyum sağlanabilmiştir (Keskinkılıç, Ağca ve Karaman, 2016). Özellikle turizm dağıtım kanallarında geleneksel seyahat acentaları ve tur operatörleri (aracılar) yerine; internet üzerinden oluşan dijital seyahat acentaları (Online Travel Agencies (OTAs)) ya da tedarikçilerin (otel, havayolu) kendi internet sitelerinden direkt satışları başlamıştır (Chang, Hsu ve Lan, 2019). Bu durum geleneksel seyahat acentacılığının, tur operatörlüğünün ve seyahat/rezervasyon dağıtım ağlarının (GDS) köklü değişimlerinin de başlangıcı olmuştur.

“Küresel (Global) Dağıtım Sistemi” (kısaca GDS) Dünya genelinde yaygın halde bulunan bütün 'Merkezi Rezervasyon Sistemlerini' (Central Reservation System) ya da 'Bilgisayarl Rezervasyon Sistemlerini' (Computerized Reservation System (CRS)) birbirine bağlayan ana sistemdir (Kurgun, Kurgun ve Güripek, 2007). CRS sistemleri turizm tedarikçilerinin (havayolu şirketleri, otomobil şirketleri ve oteller) otomatik envanter (rezervasyon) izleme sistemleridir. Buradaki en önemli konu ise, bu rezervasyon sistemlerinin bir turizm işletmesinin sahip olması ve merkezden kontrol edilmesidir. GDS kısaca birçok CRS sistemin bir araya gelmesi ile oluşmaktadır. Şekil 4'te CRS sistemlerin GDS sistemlerinin tarihsel evrimini ve 
merkezi sistemden dağıtık sisteme dönüşüm sürecini göstermektedir (Kazandzhieva ve Santana, 2019).

Şekil 4: Merkezi Rezervasyon Sistemleri (CRM) ile Global (Küresel) Dăğtım Sistemleri (GDS)

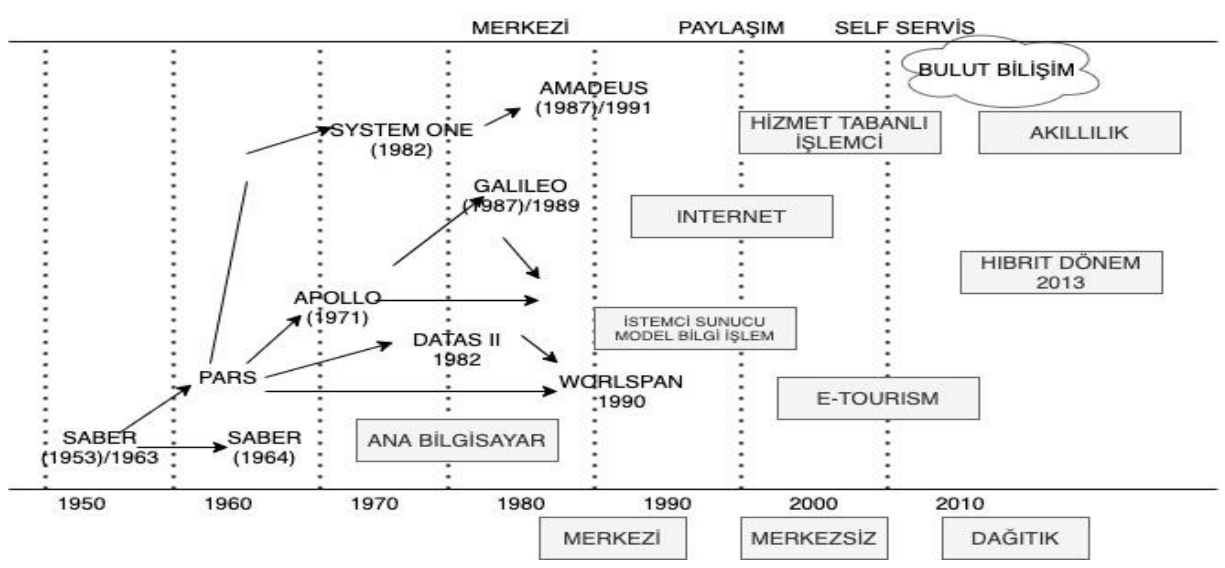

Kaynak: Kazandzhieva ve Santana (2019); yazar tarafından Türkçe'ye çevrilmiştir.

Sekil 4'te görüleceği gibi "SABER, Amadeus, Galileo ve Worldspan" olmak üzere dört işletme GDS hizmeti vermektedir (Zamyatina ve Solntseva, 2019). SABER (Semi-automated Business Research Environment) 1964 yilinda American Havayolları tarafindan kurulan ve bütün GDS'lerin başlangıcı olarak sayllan rezervasyon sistemidir. Amadeus 4 havayolu (Fransa, Iberia, Lufthansa ve SAS) tarafindan 1987 yllında İspanya'da kurulmuştur. Galileo ise 11 havayolu (Lingus, Canada, Alitalia, Austrian, BA, KLM, Olympic, Swissair, TAP, UA ve US Havayolları) tarafindan 1987 yılında kurulmuştur. Son olarak Worldspan ise Delta, Northwest ve Transworld (Transworld daha sonra American Airlines olmuştur) 1990 yılında Amerika'da kurulmuştur.

Bir seyahat acentası Dünya'nın neresinde olursa olsun rahatlık ile GDS üzerinden bir başka CRM'e bağlantı kurarak rezervasyon yapar (Kurgun vd., 2007; Vinod, 2011). CRS'lerden gelen bilgiler ile GDS'ler aracı seyahat acentalarına ulaşarak, turistin istediği rezervasyonu yapabilmelerini sağlamaktadır (Keskinkılıç vd., 2016). 2000 yılından itibaren, GDS merkezi sistem bağlantıları yerine, e-ticaret gelişimi sayesinde paylaşımcı bir yapıya geçiş yapmıştır. Bu dönem özellikle internetin ve bilgi teknolojilerinin kullanımının artmasına ve yeni turizm sistemlerinin kurulmasına neden olmuştur (Buhalis vd., 2019). Turist ile CRS/GDS, havayolu, otel ve seyahat acentalarının arasına internet ve internet üzerinden yeni sistem ile servis sağlayan turizm işletmeleri girdi (Kurgun vd., 2007; Keskinkılıç vd., 2016). Birçok eski ve köklü seyahat işletmeleri bu yeni yapıya adapte olmak için çaba gösterir iken, sayısı yadırganmayacak bir grup ise teknolojiye ve dönüşüme duyarsız kalmışlardır (Vinod, 2011). Bunun en yakın örneği ise, 2019 y1lı Eylül ayında 178 yıllık Dünya'nın ilk tur operatörü Thomas Cook'un teknolojik gelişmeler ile baş edemeyerek iflas etmesidir (Konstantinova, 2019).

\subsection{Turizmde Blokzincir Teknolojisi Alanyazın İncelemesi}

2010 yllndan itibaren turizm yeni teknolojiler ile evirilmeye devam etti. Bu yeni teknolojilerden biri olan blokzincir teknolojisi turizmde kullanım alanları bularak, yıllardır çözüm bulunamayan birçok soruna çözüm üretmeye başladı. İnternet bağlantıyı sağlarken, blokzinciri güvenli işlem yapabilmeyi sağladı.

E-turizm ekosistemi hali hazırda çok karmaşı olan geleneksel rezervasyon sistemini daha da karmaşık hala getirdi. (Pilkington, 2017). Anushya (2019) turizm işletmelerinin yaşadığı bu sorunların başında ürünün bir başka hesaba transfer edilememesi/devredilememesi; yetersiz/hatalı bagaj takip sistemi; kimlik denetleme süreçlerinde yaşanan sıkıntılar, ödemelerde yaşanan güvenlik açıkları ve çifte rezervasyonlar olduğunu belirtmektedir. Blokzinciri teknolojisinin turizm de kullanılması durumunda olabilecek yararlarını Erceg vd. (2020: 4) aşağıda yer alan maddeler ile ifade etmektedirler:

- "İlgili aktörler için mevcut olan ilgili bilgi miktarını artırmak, böylece belirsizlikleri azaltmak.

- İlgili aktörler için mevcut olan alakasız bilgi miktarını azaltmak, böylece karmaşıklıkları azaltmak.

- İlgili aktörler arasındaki bilgi asimetrisinin düzeltilmesi, böylece firsatçı davranışların sınırlandırılması.

- Aracıların dâhil olma ihtiyacını azaltmak, böylece doğrudan parasal maliyetleri azaltmak.

- Alıcılar ve satıcılar arasındaki bağlantıyı kolaylaştırmak ve böylece ticaret kalitesini arttırmak".

Amadeus (2017) tarafından hazırlanan araştırma raporunda blokzincirinin üç yıl önce kulanım alanlarını "sadeleştirilmiş ve daha güvenli yolcu kimliği belirleme, bagaj takibinin iyileştirilmesi, kullanıcı dostu müşteri sadakati programları ve seyahat acenteleri ile havayolları şirketleri arasında ödemelerin kolaylaştırılması" olarak görmekteydi. Çok kısa bir süre geçmesine rağmen, blokzincir tabanlı uygulamalar bu dört temel kullanım alanından çıkarak, çok daha geniş yelpazede kullanılmaya başlandı. Çilingir (2018) blokzinciri kullanan turizm işletmelerinin "müş̧erileri ile etkileşimi otomatikleştirmek, reklam maliyetlerini azaltmak, ortakları, hizmetleri ve ürünleri karşılıklı olarak tanıtmak, oteller, yakındaki kurumları ve müşterileri birbirine bağlayarak" hem motive edici etkileşimi artıran hem de hizmet kalitesinin artmasını sağlayacağını vurgulamaktadır. Şekil 5 'te Blokzincir teknolojisinin uygulama alanları detaylı olarak görülmektedir. 
Şekil 5: Blokzinciri Teknolojisinin Turizmde Kullanım Alanları

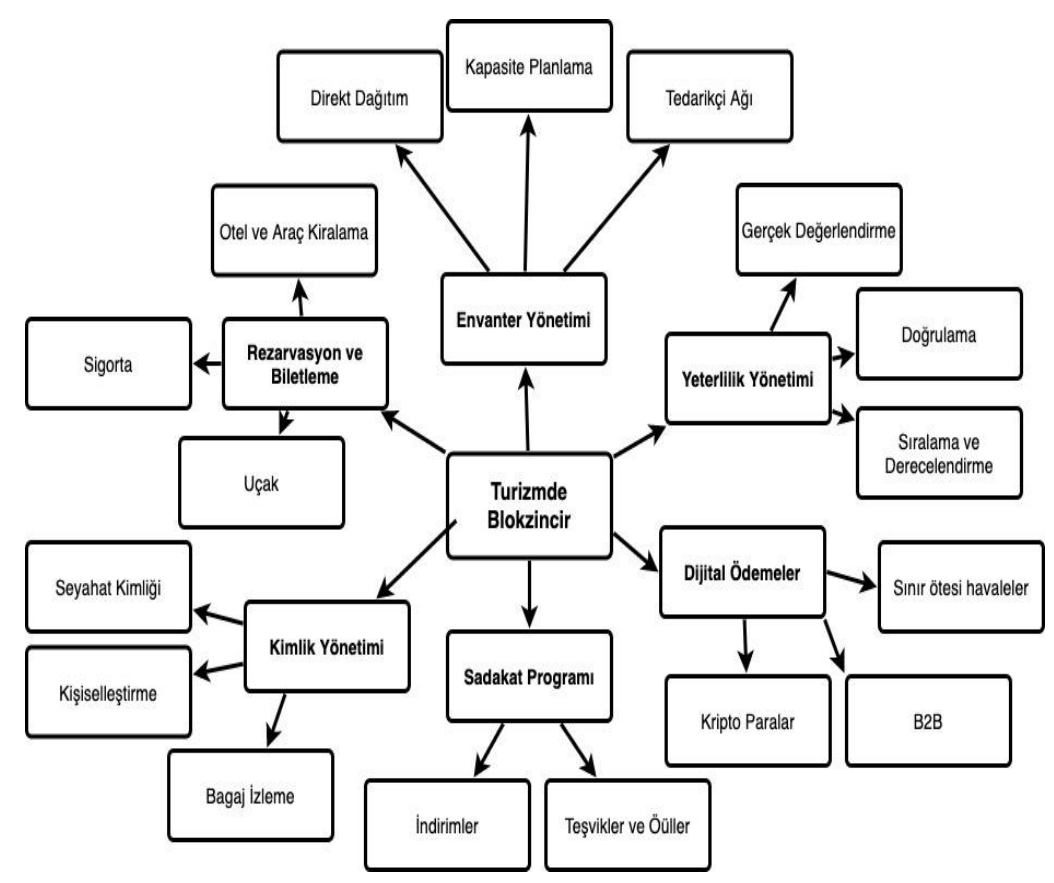

Kaynak: Erceg, Damoska Sekuloska ve Kelić (2020); Yazar tarafından Türkçe çevirisi yapılmıştır.

Turizmde blokzincir teknolojisinin kullanımı ile saydamlık, yerleşiklik, sadakat, kimlik kontrolü artacak ve sahtekârlık, çifte rezervasyon, güvensizlik ise azalacaktır (Özdemir, Ar ve Erol, 2019). Ayrıca blokzinciri kullanımı işlem ücretlerini azaltması (Valeri, 2020) dolayısı ile giderlerin ve maliyetlerin düşmesi anlamina gelmektedir. Anushya (2019) blokzinciri teknolojisinin kullanılması durumunda merkezsiz bir rezervasyon sistemi, uçaklarda gecikmelerin olmayacağı, güvenli ödeme, sorunsuz bagaj takip sistemi ve sadakat programı oluşturarak, turizmin iş yapış sisteminin kökten değişmesine neden olacağını anlaşılmaktadır. Blokzinciri teknolojisi konaklama işletmelerinde gelir yönetimi, envanter kontrolü, misafir geçmişi ve finansal yönetim gibi alanlarda kullanıma uygundur (Rejeb ve Karim 2019; Erceg, Damoska Sekuloska ve Kelić, 2020). Turizm bu uygulamaların hepsini çok karışık sistemler ile kullanmakta olup, blokzinciri teknolojisi ile hem karmaşıklık hem de güven sorunu çözülecektir (Varelas, Georgitseas, Nechita ve Sahinidis, 2019).

\subsection{Turizm İşletmelerinde Blokzincir Teknolojisi Tabanlı Uygulama Örnekle}

Turizm işletmelerinde "Bilgi ve İletişim Teknolojileri” kullanımı çok uzun yıllar öncesine dayanıyor olsa da blokzincir gibi yıkıcı teknolojilerin kullanımı ve uygulama örneklerinin yayılımı beklenildiği kadar hızlı olmadı (Rashideh, 2020). 2010 yılından itibaren teknoloji firmalarının turizm platformları ve çözüm ürünleri oluşturdukları görülmektedir (Anushya, 2019; Tham ve Sigala, 2020). 2017-2018 yılları arasında turizme yönelik hizmet veren $\mathrm{B} 2 \mathrm{C}$ ya da blokzincir teknolojisi kullanımını sağlayacak özel çözümler sunan B2B blokzincir geliştirme firma ve platformlarına ilgi artmıştır. Fakat, blokzincir ile bitcoin karıştırıldığından, blokzincirin bitcoin altında yatan bir teknoloji olarak anlaşılmadı. Bu ise blokzincir teknolojisine olan güveni sarsmaktadır. Ama diğer taraftan öncü örnekler sektörde yerlerini almaktadırlar. Tablo 2'de B2B ve B2C blokzincir tabanlı çözüm üreten platformların kuruluş yılları, kurucuları ve girişim adları ile internet siteleri bulunmaktadır. 
European Journal of Science and Technology

Tablo 2: Turizm İsletmelerinde Blokzincir Uygulama Örnekleri

\begin{tabular}{|c|c|c|c|}
\hline & Kuruluş Yılı & Kurucu & İnternet Sitesi \\
\hline \multirow{13}{*}{ 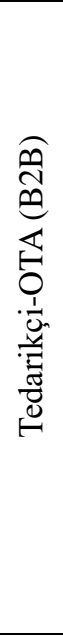 } & 2010 & Darren Wang, John Hsieh & OwlNest (https://www.owlting.com) \\
\hline & 2014 & Gregory Simon, Sean Dennis, Shannon Code & Loyyal (http://www.loyyal.com/) \\
\hline & 2015 & Clarence DeLany & Accenture (https://www.accenture.com) \\
\hline & 2015 & Armin Ebrahimi, Jeff Weitzman & ShoCard (https://shocard.com) \\
\hline & 2016 & $\begin{array}{c}\text { Gil Azrielant, Itamar Weizman, Itay Nagler, } \\
\text { Nadav Saadia, Shachar Cotani }\end{array}$ & Cool cousin (https://www.coolcousin.com) \\
\hline & 2017 & Maksim Izmaylove, Jakub Vysoky & Winding Tree (https://windingtree.com/) \\
\hline & 2017 & Ilya Orlov & TravelChain (https://travelchain.io) \\
\hline & 2017 & Jonathan Chou, Jordan Ong, Tony Tran & Beenest (https://www.beenest.com) \\
\hline & 2017 & TUI & Bed-Swap (Blokzincir tabanlı envanter sistemi ) \\
\hline & 2017 & Dennis Becker, Gregory Harris & Mobivity (https://www.mobivity.com/) \\
\hline & 2017 & $\begin{array}{c}\text { Andrew Gaidukevich, Elena Shkarubo, Nick } \\
\text { Vyhouski }\end{array}$ & MeetnGreetMe (https://meetngreetme.com) \\
\hline & 2017 & Greg Webb (CEO) & Travelport (travelport.com) \\
\hline & 2017 & Barbara Dalibard (CEO) & SITA \\
\hline \multirow{8}{*}{ 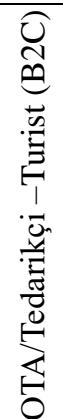 } & 2017 & Nikola Alexandrov & Lockchain/Locktrip (https://locktrip.com/) \\
\hline & 2017 & Edward Cunningham & Trippki (https://trippki.com/about-us/) \\
\hline & 2017 & Matthew Luczynski & Travala (travala.com) \\
\hline & 2018 & Sarah-Diane Eck & Sandblock (https://sandblock.io/\#about) \\
\hline & 2018 & Goh Choon Phong & Singapore Havayolları - Krispay \\
\hline & 2018 & Walter Wang & PopulStay (populstay.com) \\
\hline & 2018 & David Clarke, Allan Nahum, John Lemish & $\begin{array}{c}\text { Webjet "Rezchain" } \\
\text { (https://www.webjetlimited.com) }\end{array}$ \\
\hline & 2019 & $\begin{array}{l}\text { Kadir Özgür Oğuz, Erdem Üney, Gökhan } \\
\text { Koç, Cem Ersözlü, Eser Sevim }\end{array}$ & Further.Network (https://further.network) \\
\hline
\end{tabular}

Kaynak: Amadeus (2017); Anushya (2019); Tham ve Sigala (2020) kaynaklarından yararlanılarak yazar tarafindan Türkçeye çevrilmiş ve tablo olarak hazırlanmıştır.

Tablo 2'de görüleceği gibi, turizm işletmesş olup blokzincirini ilk kullanan TUI olmuştur (Konstantinova, 2019). 2017 yılında TUI, 'BedSwap' adını verdiği iç kontratları yönetme ve envanter kontrol mekanizması sağlayan özel blokzincir tabanlı projelerini hayata geçirdi (Vinod, 2020). TUI "Bed-Swap" özel blokzincir sistemi, şirketin talebi karşılamak için otel envanterini çeşitli satış noktaları arasında gerçek zamanlı olarak taşımasına olanak tanır. Otel gelir yönetimi altyapısına bağlanır, blokzincir sayesinde misafirlerin verilerini alarak birebir kişiselleştirir (Vinod, 2020). Ayrıca TUI, özel blokzinciri kullanarak turistik bir ürünü farklı satış noktaları arasında taşımak ve bir turizm ürününün satış marjını o andaki talep düzeyine göre gerçek zamanlı olarak arttırma firsatlarına sahip olur.

TUI'nin haricinde blokzincir tabanlı teknolojiyi kullandığını açıklayan başka bir turizm işletmesi henüz olmamıştır. Fakat turizme hizmet veren birçok teknoloji platformlarında dolaylı ya da direkt turizm ile ilgili ürünler hizmete girmeye başlamıştır. Bunun en önemli nedeni ise turizm işletmelerinin teknoloji altyapılarının blokzincir teknolojisi gibi karışık bir sistemi kurma imkânlarının olmamasıdır (Rejeb ve Karim, 2019). Bundan dolayı bu hizmeti sunan firmalar açılmıştır. 'Bitdeal.net' kripto para kullanımından özel blokzincir geliştirme, tedarik zinciri blokzincir geliştirme ve akıllı kontratlar geliştirme gibi turizm işletmelerine yönelik hizmetler vermektedir (Anushya, 2019).

Diğer bir firma ise Winding Tree, turizm işletmelerinde tedarikçilerin bir aracıya (GDS gibi) gerek kalmadan ürünlerini ve hizmetlerini sunabilecekleri tamamen merkezi olmayan blokzincir tabanlı çalışan bir platformdur. Turizm işletmelerinde blokzinciri teknolojisi kullanılarak, GDS tabanlı dağıtım ağından bağımsız tedarikçi ile satıcıyı merkezsiz ve daha az maliyetli bir platformda buluşturma özelliği vermektedir. Winding Tree sisteminde aradan kaldırılan aracı GDS olmaktadır. Komplike olan turizm dağıtım sisteminde seyahat satıcısı otel ve havayolu ile direkt bağlantı kurup, rezervasyon yapabilmektedir. Fakat sistem seyahat satıcının da aracı olarak hizmet verdiği son kullanıcı turiste ulaşan bir sistem değildir. Turistin turizm ürününe ulaşması için kurulan dağıtım sisteminde iki aracı GDS ve OTA iken, Winding Three bunu tek araciya (OTA) düşürmektedir. MeetnGreetMe, Cool Cousin, Locktrip, Trippki gibi sitelerde ise, turizm ürününü direkt turiste aracısız olarak eşten eşe sistemi ile yeni bir hizmet anlayışı getirdiği görülmektedir. Coolcousin, Locktrip ve Trippki siteler blokzincir teknolojisinin özelliklerinin yanında kripto para kullanımını mümkün k1larak kripto turizmin başlamasında etkin rol oynar.

TravelChain, işletmelere müşterilerini daha iyi tanımak ve gezginlerin en iyi müşteri hizmetini deneyimlemelerine yardımcı olmak için erişilebilir ve otantik akıllı veriler sağlayan merkezi olmayan blokzinciri tabanlı bir platform oluşturdu (Rejeb ve Karim, 2019). TravelChain, 'Akıllı Seyahat Ekosistemi' çekirdeği olma yolunda turizmin bütün paydaşları ve son kullanıcıları arasında veri alışverişine eşit erişim sağlamayı amaçlamaktadır (Polukhina, Arnaberdiyev ve Tarasova, 2019). Bir diğer önemli nokta ise, turistlerden yorum ve geri bildirimlerin doğru ve tarafsız olabilmesini sağlamak amacının yanında turistleri daha fazla yorum yapmaya teşvik etmek için de 'traveltoken' kazanma şansı vermektedir. Diğer bir yararı ise, turistlerin nasıl, ne zaman ve nereye seyahat etmeleri gerektiği 


\section{Avrupa Bilim ve Teknoloji Dergisi}

konusunda daha akıllica kararlar vermelerine yardımcı olmak için gerçek veri odaklı araştırmalar sunmasıdır.

Küçük turizm işletmelerine blokzincir tabanlı teknoloji hizmeti vermek üzere online seyahat acentası (OTA) Roomado (www.roomado.com) kurulmuştur (Nam, Dutt, Chathoth ve Khan, 2019; Antoniadis vd., 2020). Fakat, yapilan incelemede Roomado.com internet sitesinin kapanmış olduğu ve bu hizmeti veren başka bir işletmenin olmadığı tespit edilmiştir. Antoniadis vd. (2020) küçük turizm işletmelerinin aracı ile çalışmadıklarını, bundan dolayı bu tür teknolojileri kullanmaya olumlu yaklaşacaklarını belirtmektedirler.

Blokzincir teknolojisinin turizmde küçük işletmeler için kullanımını sağlayacak teknik altyapılarının olmaması ve bunu sağlayacak platformların da devamsızlığı bu teknolojiye olan güvensizliği artırabilir. Gelecek süreçte başarılı girişimler olduğu kadar başarısız girişimlerde olacaktır. Buna rağmen, blokzinciri teknolojisinin kullanım alanı turizm işletmeleri için oldukça geniş bir yelpazeye sahip olacaktır. Blokzinciri teknolojisinin turizm işletmelerinin kullanımında merkezsizlik (eşten eşe ağ, merkezsiz kontrol, aracısız); açıklık (şeffaflık, değişmezlik, zaman damgası); güvenlik (daha az savunmasız, güvenli işlem, inkâr edilemeyen); maliyet azaltmak (üçüncü tarafın olmadığg, işlem ücretlerinin düştüğ̈) ve hızlı işlem (işlem süreçlerinin otomasyonu, aerodinamik süreçler, tek bir hata noktasının olmaması) yapabilme imkânları oluşacaktır (Rejeb ve Karim, 2019).

\section{Sonuç}

Turizmin geleneksel yapısında, turistin bilgi toplama, satın alma ve deneyim sürecinde tedarikçi ile turist arasında birden fazla aracı vardır. Tedarikçiler tarafından 'Bilgi ve İletişim Teknolojileri' kullanılarak CRS/GDS sistemleri ile rezervasyon ve envanter kontrolü gerçekleşir. Turistin bir turizm ürünü hakkında bilgi alması ve sonrasında satın alabilmesi için geleneksel yöntemler de seyahat acentalarının ya da tur operatörlerinin aracılığına ihtiyaç duyulmaktadır. İnternet ile tedarikçiler, seyahat acentaları (OTA) ve tur operatörleri turiste online platformlar üzerinden direkt hizmet ve satış gerçekleştirir. İnternet ile bu sistem nispeten değişse de gerçek anlamlı bir yapısal değişiklik olmamıştır. Bu araştırmada bilgi ve iletişim teknolojilerinden $\mathrm{y} 1 \mathrm{kic1}$ bir teknoloji olan blokzincir teknolojisine geçiş süreci incelenerek, pratikte kullanılan uygulama örnekleri ile yapısal değişikliklerin nasıl olacağı tespit etmek amaçlanmıştır.

Blokzinciri teknolojisi kripto para ile karıştırılmaması gerektiğidir. Blokzinciri kripto para transferlerinin kullanıldığı bir teknolojidir ve finans haricinde kullanım alanları bulmaya başlamıştır. Turizm bunlardan sadece biridir. Turizm çok karmaşık ekosistemine sahiptir ve bu tüketici için güven sorunu, bilgi kirliliği ve suiistimale açıklık yaratmaktadır. Rashideh (2020) blokzinciri teknolojisinin turizmde aracı rolünü tamamen ortadan kaldıracağını hatta yeni aracıların girmesini de engelleyeceğini belirtmektedir. Turizm tedarikçilerinin ve turistlerin de aracısız etkileşim içinde olabilmesi, blokzincir teknoloji kullanılarak oluşacak sistemlerle mümkün olacaktır. Tham ve Sigala (2020) blokzincirinin turizmin sürdürülebilir geleceğinde önemli bir role sahip olacağını belirtmektedir. Blokzincir teknolojisi sayesinde maliyetler azalacak ve verimlilik artacaktır. Blokzincir teknolojisi içine entegre edilecek kriptopara ödeme yöntemleri ile güvenli ve hılı para transferi sağlanacaktır. Blokzincir teknolojisi ile kurulmuş, kontrol edilebilen işlem geçmişi ile şeffaflık oluşacaktır.

Turistlerin en büyük sorunu karmaşık ve çok fazla bilgi karşısında yaşadığı güvensizlik durumudur. Özellikle turiste yanlış ya da çifte rezervasyon yapma, eksik bilgi verme gibi durumlardan yüksek seyahat maliyetleri ve güven sorunları turistlerin seyahat kararları ile satın alma eğilimlerini etkilemektedir. Turist seyahatinin rahat, keyifli ve aynı zamanda uygun maliyetli olmasını ister. Ücretler, kötü yorumlar, rezervasyon usulsüzlükleri ve sorunları seyahati daha da kötüleştirir. Ayrıca tüm turizm işletmeleri üzerinde kötü bir kullanıcı izlenimi bırakır.

Blokzincir, turizmde aracılık düzeyini tamamen ortadan kaldırarak maliyet ve güven konusunda avantajlar sunan güçlü bir teknolojidir. Blokzinciri teknolojisi turizme şeffaflık ve güvenlik sağlayarak, turistlerin daha rahat, sıklıkla ve güvenli alışveriş yaparak seyahat etmelerinde önemli bir rol oynayacaktır (Anushya 2019). Vinod (2020) blokzincirinin turizmde kabul edilebilirliğinin çok erken aşamalarında olduğunu vurgular. Kısmen bu doğru olsa da bilgi ve iletişim teknolojisi altyapısı ve uzun yıllar farklı teknolojilerin kullanımı dolayısı ile adaptasyon beklenilenden daha hılı olabilir. Blokzinciri kullanımı ile turistler seyahat öncesi, esnasında ve sonrasında zaman kazanma, maliyeti azaltma ve şeffaf bir şekilde her şeyi kontrol edebilme açısından daha memnun edici tatiller planlayabilirler. Blokzincirin başarısında son kullanıcı deneyimi çok önemlidir. Seyahat deneyimleri, müşteri verilerinin gizliliğini ve güvenliğini korumak, blokzincir ile yeni bir seviyeye ulaşırsa çok hızlı bir şekilde benimsenecektir.

Turizm işletmeleri ise blokzincir teknolojisi kulanımı ile envanter kontrol, güvenli işlem ve az maliyet ile verimliliği artırabilir. Önümüzdeki on yıl içinde, güvenlik, yüksek hacimli işlem işleme, havayolu planlama ve havayolu operasyonları iş süreci değişiklikleri alanlarındaki birçok engelin aşılması gerekecektir. Blokzincir teknolojisinin hızlı adaptasyonu kitlesel olarak benimsenmesi ile mümkün olacaktır. Blokzinciri teknolojisinin kullanımının turistler ve turizm işletmeleri için verimliliği artırarak seyahat planının başından sonuna kadar bütün işlemlerde harcanan zamanı, maliyeti, güveni ve şeffaflığı sağlayacak bir teknoloji olması avantajlar arasında sıralanabilir. Turizm işletmeleri hem turist ile direkt iletişimde olacaklar hem de işlemlerin hepsi üst düzey otonom ve güvenlik ile gerçekleşecek. Blokzincir teknolojileri, turizmin daha sağlıklı ve güvenli ortam içerisinde yapılmasını sağlayacaktır. Blokzincir teknolojisi ile turizm işletmelerinin iş modeli, para transfer sistemleri, güvenlik ve performans artırmada yardımcı olacaktır (Rashideh, 2020).

Blokzinciri teknolojisi çok faydalı görüldüğü kadar dezavantajları da bulunmaktadır. Gatteschi vd. (2018) bu dezavantajları ölçeklenebilirlik, düşük performans, enerji tüketimi, bilinmeyen durumlarda ya da kripto para kaybedilmesi durumunda iletişime geçilecek birinin olmaması gibi birçok dezavantajları olduğuna dikkat çekmektedirler. Bu araştırmada turizm işletmeciliğinin blokzincir teknoloji uygulanması ile etkilenecek üç kategori bulunmaktadır, bunlar;

1) Blokzinciri teknolojine karşı turizm ekosisteminde bulunan aracıların tutumları ve algıları;

2) Blokzincir teknolojisinin turizmde aracılığı ortadan kaldırma özelliği ve faydaları;

3) Blokzincir ile merkezsiz, şeffaf işlem yaparak turistin güvenini artıran yeni modellerin oluşması. 
Sayıları gün geçtikçe artmaya başlayan turizm blokzincir uygulamalarının örnekleri yavaş yavaş çoğalacaktır. Blokzincir turizm uygulamalarının B2B ve B2C olarak iki farklı kullanım alanı bulunmaktadır. Fakat turizm işletmelerinden sadece TUI'nin blokzinciri teknolojisini üreten ve kullanan olması ve blokzincir çözümleri üretenlerin aslında teknoloji firması ya da platformları olması dikkat çekicidir. Turizm işletmelerinin blokzincir gibi karışık teknolojileri kullanmak için teknolojik altyapılarının olmaması ve bunun için gerekli yatırımların yapılmamış olması ise bu teknolojinin hızla ilerlemesinde bir engel oluşturmaktadır. Turizm işletmelerinde yeni teknolojilerin sürekli araştırılıp geliştirileceği AR-GE departmanları ve uygulama merkezlerinin olmaması da bu konuda geride kalmalarına neden olmaktadır. Küçük turizm işletmelerin araştırma yapmaya bütçe ayırmaları mümkün olamaz gibi gözükse de üniversiteler ile iş birliği yapılarak çözümler üretilebilir. Geleceği şimdi yakalamak için, turizm işletmelerinin üniversiteler ile iş birliğinde teknoloji AR-GE çalışmalarını destekleyerek turizme uygun blokzincir teknolojisi 4.0 geliştirilmesi gerekmektedir.

Bugüne kadar kabul edilen sıkıntılara dezavantaj olarak görmek yerine, potansiyel çözülmesi beklenen problemler olarak görülmelidir. Bugün için çözülemeyen sorunlar gelecekte keşfedilecek yeni teknolojiler, buluşlar ve inovasyonlar anlamına gelmektedir. Bu çalışmanın odaklandığı alan blokzincirinin turizm işletmelerine aracisız, merkezsiz ve şeffaf işlem yapabilme imkânı vermesi ve bu işlemlerin yapılabilmesine imkân tanıyan sistemlerin benimsenmesi olduğundan sınırlılıkları da bulunmaktadır. Diğer disiplinlerde, blokzincir teknolojisinin benimsenmesi ile ilgili farklı sorunlar ortaya çıkabilir. $\mathrm{Bu}$ nedenle, bu sonuçları daha geniş ölçekte doğrulamak için nicel yöntemi kullanmak ve sonuçları mevcut bulgularla karşılaştırmak için başka çalışmalara ihtiyaç vardır. İleride turizm uygulamalarında blokzincir teknolojisinin işlem zamanı, fazla elektrik harcaması gibi dezavantaj gözüken durumların nasıl çözümlenebileceği üzerine araştırmalar yapılabilir.

Ayrıca, ileride çok yeni kurulan blokzincir tabanlı turizm çözümlerin ve uygulamaların yapıları, çalışma prensipleri ve sonuçları incelenebilir. Turizmde blokzincir teknolojisi kavramı geliştirilerek turizme özgü modeller ve çözümler üretilmelidir. Turizme özgü bir model geliştirilerek prototip çalışmaları desteklenebilir. Turizm işletmeleri turizm blokzincir modeline ve bu modelin nasıl uygulanacağı konusundaki rehberlere çok ihtiyaç duyacaktır. Özellikle, blokzinciri turizm uygulamalarının faydalarının örnek olay incelemesi ile analiz edilmesi blokzincirinin daha iyi anlaşılabilmesi için önemlidir.

$\mathrm{Bu}$ çalışma ile turizm blokzincir kavramı detaylı olarak ortaya konulmuştur. Blokzincir teknolojisi yıkıcıdır ve turizmde devrim yaratabilecek özellikleri vardır. Turizm işletmelerinin dinamik yapısı ve işlem hacmi ile blokzinciri teknolojisinde sadece uygulama örnekleri görülecek bir alan olmayacağını ortaya koymaktadır. Blokzinciri teknolojisi turizmi yapısal olarak değiştirirken bunu aracısız, güvenli, şeffaf, merkezsiz, değişmeyecek, inkâr edilemeyen işlemler ile düşük maliyet ve işlem ücretleri sağlayarak; işletme sahibi, çalışan ve misafïlerin memnuniyetini artıracak şekilde yapacak olmasıdır. Sonuç olarak, blokzincir teknolojisinin turizmde iş modeli, iş firsatları ve aracıların geleceği üzerinde büyük değişim gerçekleştirebilir. $\mathrm{Bu}$ çalışma ile turizm işletme sahipleri, yöneticiler ve araştırmacılar için işletmelerde verimliliği artıracak stratejilerin geliștirilmesini ve uygulanmasını destekleyecek blokzinciri teknolojisinin erken benimsenmesinde yol gösterici olacaktır.

\section{Teşekkür}

Makaleyi değerlendiren hakemlere değerli katkılarından dolayı, dergi editörleri Prof. Dr. Osman Sağdıç, Prof. Dr. Hüseyin Toros, Prof. Dr. Ahmet Doğan ve dergi sekreteryasını yürüten Sayın Abdulkadir Şahiner'e yayın sürecindeki yardımları için teşekkür ederim.

\section{Kaynakça}

Amadeus. (2017). Blockchain: Harnessing Its Potential in Travel. $25 \quad$ Mart 2020 tarihinde

https://amadeus.com/en/insights/researchreport/blockchain-harnessing-its-potential-in-travel adresinden erişildi.

Angın, P. (2020). Blockchain-Based Data Security in Military Autonomous Systems. Avrupa Bilim ve Teknoloji Dergisi, Ejosat Özel Sayl 2020 (ISMSIT), 362-368.

Anushya. (2019). How Blockchain Technology can Transform Travel and Tourism Industry? 24 Haziran 2020 tarihinde https://Www.Bitdeal.Net/Blockchain-In-Travel-And-Tourism adresinden erișildi.

Antoniadis I., Spinthiropoulos K., ve Kontsas S. (2020). Blockchain Applications in Tourism and Tourism Marketing: a Short Review. İçinde A. Kavoura, E. Kefallonitis, P. Theodoridis (Editörler), Strategic Innovative Marketing and Tourism (ss. 375-384). Cham: Springer.

Avunduk H. ve Aşan H. (2018). Blok Zinciri (Blockchain) Teknolojisi ve İşletme Uygulamaları: Genel Bir Değerlendirme, Dokuz Eylül Üniversitesi Iktisadi ve İdari Bilimler Fakültesi Dergisi, 33 (1), 369-384.

Aydar, M. ve Çetin, S. (2020). Blokzincir Teknolojisinin Sağlık Bilgi Sistemlerinde Kullanımı. Avrupa Bilim ve Teknoloji Dergisi, (19), 533-538.

Brandenburger M., Cachin C., Kapitza R. ve Sorniotti A. (2018). Blockchain and Trusted Computing: Problems, Pitfalls, and a Solution for Hyperledger Fabric, CoRR, arXiv, 1805.08541, 1-13.

Buhalis D., Harwood T., Bogicevic V., Viglia G., Beldona S. ve Hofacker C. (2019). Technological Disruptions in Services: Lessons from Tourism and Hospitality, Journal of Service Management, 30 (4), 484-506.

Chang Y.W., Hsu P.Y. ve Lan Y.C. (2019). Cooperation and Competition between Online Travel Agencies and Hotels, Tourism Management, 71, 187-196.

Çilingir T. (2018). Turizmin Geleceği Blockchain Teknolojileriyle Değişiyor. 31 Eylül 2019 tarihinde https://Www.Dijitalbiz.Com/Turizmin-Gelecegi-BlockchainTeknolojileriyle-Degisiyor/ adresinden erişildi.

Durbilmez S.E. ve Türkmen S.Y. (2017). Blockchain Teknolojisi ve Türkiye Finans Endüstrisindeki Durumu, Finans Ekonomi ve Sosyal Araştırmalar Dergisi (FESA), 4 (1), 3045.

Erceg A., Damoska Sekuloska J. ve Kelić I. (2020). Blockchain in the Tourism Industry-a Review of the Situation in Croatia and Macedonia, Informatics, 7 (5), 1-16.

Gatteschi V., Lamberti F., Demartini C., Pranteda C. ve Santamaría V. (2018). Blockchain And Smart Contracts For Insurance: is The Technology Mature Enough?, Future Internet, 10 (20), 1-16. 
Guo Y. ve Liang C. (2016). Blockchain Application and Outlook in the Banking Industry, Financial Innovation, 2 (24), 1-12.

Gültekin Y. (2017). Turizm Endüstrisinde Alternatif Bir Ödeme Aracı Olarak Kripto Para Birimleri: Bitcoin, Güncel Turizm Araştırmaları Dergisi, 1 (2), 96-113.

Jantoń-Drozdowska E. ve Mikołajewicz-Woźniak A. (2017). The Impact of the Distributed Ledger Technology on the Single Euro Payments Area Development, Equilibrium Quarterly Journal of Economics and Economic Policy, 12 (3), 519535.

Karaarslan E. ve Akbaş M.F. (2017). Blokzinciri Tabanlı Siber Güvenlik Sistemleri, Uluslararast Bilgi Güvenliği Mühendisliği Dergisi, 3 (2), 16-21.

Karaarslan, E. \& Konacakli, E. (2020). Data Storage in the Decentralized World: Blockchain and Derivatives. Gulsecen S., Sharma S., Akadal E. (Eds.), Who Runs the World: DATA içinde (ss. 37-69). İstanbul, İstanbul Üniversitesi Yayınları.

Kazandzhieva V. ve Santana, H. (2019). E-Tourism: Definition, Development and Conceptual Framework, Turizam: Međunarodni Znanstveno-Stručni Časopis, 67 (4), 332-350.

Keskinkılıç M., Ağca Y. ve Karaman E. (2016). İnternet ve Bilgi Sistemleri Kullanımının Turizm Dağıtım Kanallarına Etkisi Üzerine Bir Uygulama, İşletme Araştırmaları Dergisi, 8 (4), 445-472.

Konstantinova S. (2019). Digital Transformation in Tourism, International Journal of Knowledge, 35 (1), 187193.

Kösesoy İ. (2019). Nesnelerin İnterneti Güvenliğinde Blok Zinciri Uygulamaları, Veri Bilimi, 2 (1), 1-9.

Kurgun O. A., Kurgun H. ve Güripek E. (2007). Turizm Pazarlamasında Küresel Dağıtım Sisteminin (GDS) Stratejik Rolü ve Önemi, Dokuz Eylül Üniversitesi Sosyal Bilimler Enstitüsü Dergisi, 9 (1), 262-274.

KVK (2019). 2019 Tarih ve 2019/143 Sayılı Karar Özeti. 29 Ağustos $2019 \quad$ tarihinde https://Kvkk.Gov.Tr/Icerik/5406/Kurul-Karar-Ozetleri adresinden erişildi.

Lin I.C. ve Liao T.C. (2017). A Survey of Blockchain Security Issues and Challenges, International Journal of Network Security, 19 (5), 653-659.

Lu Y. (2018). Blockchain and the Related Issues: A Review of Current Research Topics, Journal of Management Analytics, 5 (4), 231-255.

Mustaçoğlu, A. (2018). Blockchain-Based Data Sharing and Managing Sensitive Data. Avrupa Bilim ve Teknoloji Dergisi, (14), 235-240.

Nakamato S. (2008). Bitcoin P2P E-Cash Paper. 26 Ağustos 2019 tarihinde https://Www.Metzdowd.Com/Pipermail/Cryptography/2008October/014810.Html adresinden erişildi.

Nam K., Dutt C.S, Chathoth P. ve Khan M.S. (2019). Blockchain Technology for Smart City and Smart Tourism: Latest Trends and Challenges, Asia Pacific Journal of Tourism Research, 24 (5), 71-87.

Özdemir A. I., Ar I.M. ve Erol I. (2019). Assessment of Blockchain Applications in Travel and Tourism Industry, Quality ve Quantity, 53, 1-15.

Önder I. ve Treiblmaier H. (2018). Blockchain and Tourism: Three Research Propositions, Annals of Tourism Research, 72, 180-182.

Özpınar, A. (2020). Dinamik Tüketici Talep Yönetimi Yapabilen Blokzincir/Kripto Para Tabanlı Elektrik Piyasası İşletme
Modeli. Avrupa Bilim ve Teknoloji Dergisi, EJOSAT Özel Say1 2020 (HORA), 434-441.

Pilkington M. (2017). Can Blockchain Technology Help Promote New Tourism Destinations? The Example of Medical Tourism in Moldova, SSRN Electron Journal. 26 Mart 2019 tarihinde https://ssrn.com/abstract=2984479 adresinden erişildi.

Rashideh, W. (2020). Blockchain technology framework: Current and future perspectives for the tourism industry. Tourism Management, 80, 104-125.

Rejeb A. ve Karim R. (2019). Blockchain Technology in Tourism: Applications and Possibilities, World Scientific News, 137, 119-144.

Sirka S., Erdelyi J., Čičák P. ve Jelemenská K. (2019). Survey on Security Threats and Algorithms in Internet of Things Environment. 17th International Conference on Emerging Elearning Technologies and Applications (ICETA) (ss. 721726). Slovakia: Starý Smokovec.

Tanriverdi M., Uysal M. ve Üstündağ M.T. (2019). Blokzinciri Teknolojisi Nedir? Ne Değildir?: Alanyazın İncelemesi, Bilişim Teknolojileri Dergisi, 12 (3), 203-217.

Taş O. ve Kiani F. (2018). Blok Zinciri Teknolojisine Yapılan Saldırılar Üzerine Bir İnceleme, International Journal of Informatics Technologies, 11 (4), 369-382.

Tham A. ve Sigala M. (2020). Road Block (Chain): Bit(coin)s for Tourism Sustainable Development Goals?, Journal of Hospitality and Tourism Technology, 11 (2), 203-222.

Ulusoy T. ve Dönmez C.Ç. (2018). Turizm Endüstrisine Alternatif Bir Firsat Yaklaşimi Olarak Blockchain Teknolojisinin Kullanilmasi. 4. Uluslararasi Türk Dünyasi Turizm Sempozyumu (s. 236-243). Türkiye: Kastamonu.

Valeri M. (2020). Blockchain Technology: Adoption Perspectives in Tourism. V. Ratten (Editör), Entrepreneurship and Organizational Change Managing Innovation and Creative Capabilities içinde (s. 27-35). Cham: Springer.

Varelas S., Georgitseas P., Nechita, F. ve Sahinidis A. (2019). Strategic Innovations in Tourism Enterprises through Blockchain Technology. A. Kavoura, E. Kefallonitis ve A. Giovanis (Editörler), Strategic Innovative Marketing and Tourism içinde (s. 885-891). Cham: Springer.

Vinod B. (2011). The Future of Online Travel, Journal of Revenue and Pricing Management, 10 (1), 56-61.

Vinod B. (2020). Blockchain in Travel, Journal of Revenue and Pricing Management, 19 (1), 2-6.

Yıldız S. ve İbiş S. (2019). Turizm Endüstrisinde Yeni Yaklaşımlar: Dağitik Kayit Defteri Teknolojisi. Ş. Özdemir, E. Pelit ve A. Avan (Editörler), 19. Ulusal Turizm Kongresi Bildiriler Kitabı içinde (ss. 855-864). İzmir: Egeus Matbaacilık.

Zamyatina N.A. ve Solntseva O.G. (2019). Hotel Tech Ecosystem: Adaptations to Online Distribution. E.G. Popkova ve B.S Sergi (Editörler), ISC 2019 Scientific and Technical Revolution: Yesterday, Today and Tomorrow içinde (ss. 194-204). Cham: Springer. 